\title{
ACTIVE-LEARNING METHODS FOR CONTROL ENGINEERING TEACHING USING WEB APPLICATIONS
}

\author{
A. González Sorribes, E. Del Val Noguera \\ Departamento de Informática e Ingeniería de Sistemas, Universidad de Zaragoza, Escuela \\ Universitaria Politécnica de Teruel (SPAIN)
}

\begin{abstract}
The development of active-learning methods is strongly proliferating nowadays in Higher Education studies. Roughly speaking, active learning can be understood as a way of learning in which students are more directly involved in the learning process. It is commonly accepted that, in contrast to traditional methods, substantial improvement of the own learning process is achieved through active methodologies. In particular, teachers must address an extra effort to engage the interest of students when faced with subjects provided with strong theoretical background (such as automatic control related topics). Indeed, one of the main drawbacks reported by the own students is their difficulty to connect real engineering application and theoretical lessons. In this paper, we present an active learning method conceived for automatic control subjects with the aid of virtual laboratories compatible with a wide range of web browsers for this end. In a first stage, some real engineering problems for students in the classroom are raised. Through a suitable follow-up of intermediate results and the appropriate discussions, teachers will be able to obtain an immediate feedback while evaluating the quality of learning at each stage. It is worthwhile mentioning that virtual labs are developed using the standard web interactive programming language HTML and Javascript, which only requires a web browser to be executed. Hence, in comparison to previous academic years, it is expected to better promote the usefulness of the control engineering for the students' careers with high degree of autonomy for selfscheduling homework and low cost resources, while improving the self-motivation and long-term quality of learning.
\end{abstract}

Keywords: Motivation, autonomy, virtual lab, interaction, active-learning, university.

\section{INTRODUCTION}

Traditional learning methods are still considered the most effective way to quickly transmit a great variety of information to big groups of students. Nevertheless, under traditional methods, students passively receive information from teachers. Hence, in most cases, they learn it by rote rather than on a deeper understanding [1]. This process is known as passive learning [2], and has the disadvantage that, when lecturing, the instructor organizes and presents essential information without receiving student feedback. In addition, this approach does not facilitate students to distinguish for themselves what information could be more relevant in a particular context, and how to apply it in real-life problems. Other drawback of passive learning approaches is that only lower-order tasks of learning, such as described using Bloom's taxonomy [3], are engaged. It means that students could acquire the ability to simply remember what they have learnt, whereas high-order levels of learning (that is to say: analysis, synthesis and evaluation) are not ensured to be fulfilled, that is to say, they will be less active in interpreting and integrating the ideas and concepts that were previously acquired. Hence, in many cases, knowledge is poorly organized and exhibits lacks coherence and integration, leading to possible failures during the process of transferring knowledge to new problems and making inferences.

In contrast, active-learning methods allow students to be more directly involved in the learning process, promoting them to discuss and exchange different points of view, help other colleagues in cooperative tasks, and constructing their knowledge by the "learning-by-doing" [4]. In this way, high-order tasks of learning are granted to be fulfilled. According to Mayer [5], a "meaningful learning" can be understood as a way of learning which produces organized, coherent, and integrated mental models that allow students to make inferences and apply knowledge.

Other key aspect to take into account in the learning process is the self-motivation, which is closely related to their intrinsic motivation. Following the convention of Deci [6], intrinsic motivation can be understood as the need to be effectively self-determining [7] and to have a meaningful impact on one's environment. To facilitate one's intrinsic motivation, learning methods should reinforce students' 
curiosity, interest and persistence at learning tasks, rather than be guided by external events, such as achieving a reward or simply succeed in the evaluation process.

For the reasons above pointed out, the development of active-learning methods is strongly proliferating nowadays in Higher Education studies with the objective of enhancing the long-term quality of learning. Nevertheless, the challenge that must be faced is how to smoothly integrate these methodologies in the traditional learning context with the objective of not being quite disruptive with respect to previous academic courses. At the same time, all contents must be guaranteed to be taught in time which makes not easy the integration of active methodologies at a first glance.

\section{CONTEXT}

This paper is contextualized in the field of control engineering, where even students having a strong vocation in this field might find themselves uninterested in some particular subjects. This is the case of subjects involving strong theoretical background and topics whose deep comprehension cannot be taken for granted. In these situations, teachers must face the challenge of engaging the interest of students and promoting the usefulness of the subject for their careers.

The active-learning method described in this paper is focused on context of the third-year of the Degree in Industrial Electronics and Automatic Control Engineering at Universidad de Zaragoza. In particular, we have implemented the described method for the first time in a subject titled as "computer-based control engineering".

The original idea was conceived on the basis of some inquiries carried out from the own students of previous academic courses, where most of them pointed out some difficulty to connect real engineering application and theoretical lessons which justify the necessity of better highlight the real-life application of what they are learning.

Due to evident time-scheduling constraints, the only way to transmit all contents in the available teaching period is to resort to traditional methods based on passive learning. This is the reason why active-based learning methods have been not implemented till now. This situation, which is very common in other teaching subjects provided with strong theoretical background, implies an extra effort to engage the interest of students and potentiate their intrinsic motivation.

Moreover, resources limitation frequently represents a drawback when implementing active-learning methods. Nevertheless, one of the remarkable advantages of the proposed methodology is that no extra investment is required since we resort to free available technology.

Next subsection gives a brief insight of the available resources that has been used to develop our proposal.

\subsection{Resource description}

Easy Java Simulations (EJS) is a non-commercial open source (free of charge) software tool that was created by science teachers to improve teach and learn science [8]. EJS has the key advantage that allows users to generate simulations using their knowledge of the scientific model through a graphical drag-and-drop interface. Hence, users are not required to possess strong programming skills. It is also worth mentioning that once an EJS project is created, it can automatically be casted into JAVA Applets [9] or HTML/Javascript code [10], which can be executed in a web browser without being necessary to install extra plugins. Consequently, EJS can serve as an effective teaching and learning tool if used in an appropriate pedagogical setting; for instance, to illustrate students in the classroom how a given scientific process works or even to show them how to create their own simulations in order to allow them to contrast and validate their theoretical conclusions.

EJS is being currently exploited to create virtual and remote laboratories in multiple teaching disciplines, such as control engineering [11], robotics [12], physics [13], etc. The main objective of such projects is to share resources between different universities allowing thus to enrich the variety of applications for students with minimum cost [14]. The most general implementation of virtual and remote labs requires the use of some commercial tools such as MATLAB or LABView.

For our purpose, we will release from these last requirements by only using the front-end application, that is to say, the web application without establishing any connection with a central server. All resources will be available to students in the Moodle platform, and once they are downloaded, students will be 
able to work with them in their local computers without being necessary to have internet connection all the time.

\subsection{Objective}

In the context of the teaching subject under discussion in this paper, the objective is that students effectively learn how to implement control algorithms in a computer starting from some specifications of transient and permanent closed-loop performance to be fulfilled. Despite of the apparent simplicity on the objective description, there are a strong mathematical background behind which makes this task being far from trivial. For this reason, we have proposed the active methodology described in the next section with the objective to help them to connect theory and practice during the learning process and choose the suitable tool at each stage of the problem to be solved.

\section{DEVELOPMENT OF ACTIVE METHOD}

The active method proposed here follows the paradigm of problem-based learning (PBL) [15]. PBL began at McMaster University in Canada in 1969 for the study of medicine, bringing then a novelty unlike any other in medical education at the time. Since then, it has been successfully implemented into many medical programs as well as into other programs such as economics, law and psychology. In its original form, a PBL curriculum is delivered in a set of problems which provides the starting point for the learning process. In our case, two control engineering problems are exposed in the classroom. A brief description about them is given in the classroom into more than 20 minutes. During its presentation, teachers should engage the students' interest of such proposals by promoting the curiosity as if it were a game or a challenge to fulfill. Hence, the idea is to potentiate the intrinsic motivation, rather than being under pressure that might compromise the natural way to engage them motivation. The following key aspects have been taken into account in the proposed methodology:

1 From the perspective of students:

1.1 The proposed work is not mandatory, but it might allow students to improve its final score after evaluation, provided that a minimum level is achieved in the final exam. In this way, the motivation for students is only based on positive reinforcing, allowing them to be guided by their self-motivation and curiosity, rather than mere imposition.

1.2 Students have the option to freely choose one of the two proposed works. Hence, the can feel more self-control about their own learning process.

1.3 Students are allowed and encouraged to propose other examples that would be welcome for future proposals.

1.4 Students can work in the proposals at any place in their local computers without being subjected to timetable constraints. Additionally, the virtual labs developed here operate offline, that is to say, without being necessary to exchange data with a central server.

2 From the perspective of investment, it is worth mentioning on the basis of the above arguments that the proposal does not require to make investments in hardware resources or software licenses, since the virtual labs which will be used can be locally executed at each computer by means of a web browser without the necessity of installing extra plugins or even having internet connection all the time.

\subsection{PBL Description}

This section gives a detailed description of the two proposed computer based control engineering problems in the classroom, which have been previously implemented for students in HTML/Javascript format using EJS:

\subsubsection{Problem 1: Computer-based control of an air levitator}

In the first proposed work, the objective is to implement a computer-based algorithm to automatically set the height of some levitating piece at some prescribed value by controlling a wind-turbine placed at the bottom of a guiding tube inside which such levitating piece is contained (see Fig. 1). Moreover, through a camera and some processing image algorithm the height of the levitating piece is measured at each sampling period Ts. Once the measurements are available, students must design a control algorithm using the analytical tools acquired in theoretical lessons. The control action finally consists in 
a digital signal that will be transformed into voltage supply for the wind-turbine through a digital-to-analog (AD) converter. The dynamic equations, together with the nominal values for physical parameters, are provided:

$$
\begin{aligned}
& \dot{w}=\frac{\kappa u-w}{\tau} \\
& \ddot{x}=g\left(\left(\frac{w-\dot{x}}{v_{e}}\right)^{2}-1\right)
\end{aligned}
$$

where $\mathbf{x}$ is the height of the piece, $\mathbf{u}$ and $\mathbf{w}$ is the input voltage and the angular speed for wind-turbine, and the rest of physical parameters are given below:

$$
\begin{aligned}
& g=9.81 \mathrm{~m} / \mathrm{s} 2, \quad r=0.05 \mathrm{~m}, \quad m=0.01 \mathrm{~kg} \\
& \tau=0.12[\mathrm{~s}], \quad \kappa=1.35[1 / \mathrm{V} \bullet \mathrm{s}] \\
& \alpha=(0.5)(1.15)(1.23) \pi r^{2}, \quad v_{e}=\sqrt{\frac{m g}{\alpha}}
\end{aligned}
$$
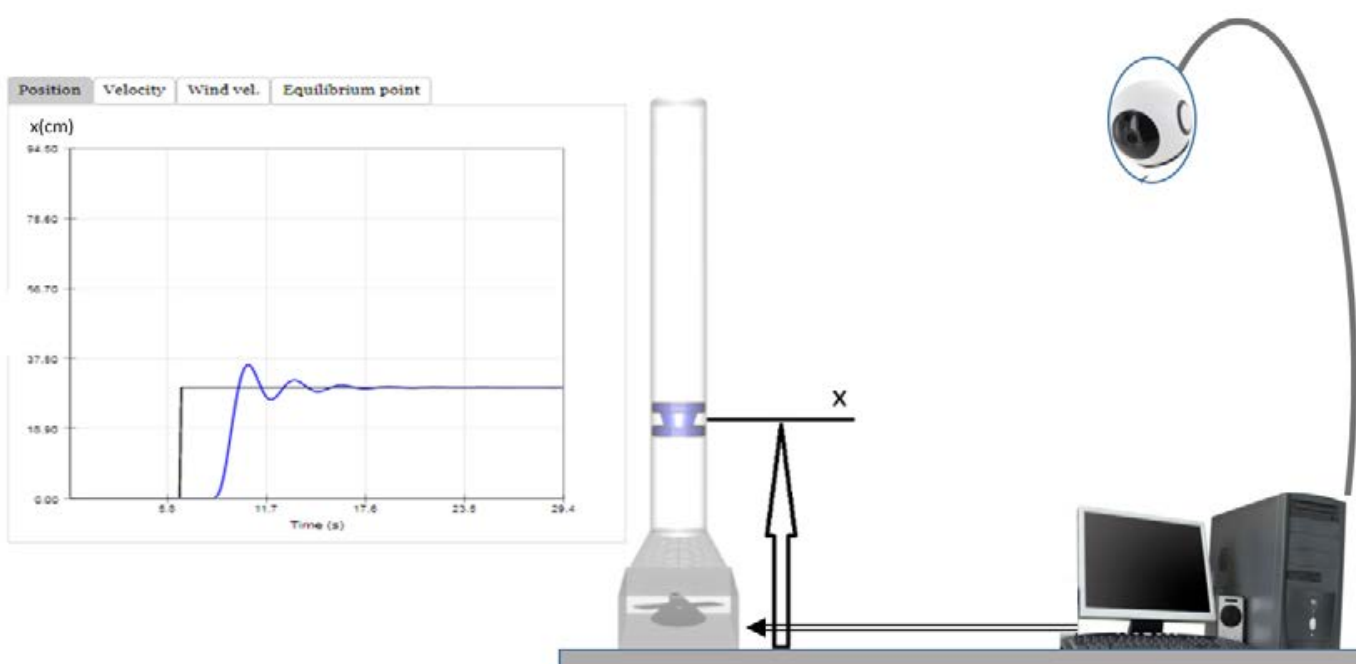

Figure 1. Computer-based control of an air levitator where the height of the levitating piece (namely " $x$ ") is measured by a camera.

\subsubsection{Problem 2: Computer-based control of the position of a servomechanism}

In the second proposed work, the objective is to implement a computer-based algorithm to control the angular position of a servomechanism (see Fig. 2). Analogously, a digital sensor that provides measurements of the angular position at each sampling period T is assumed to be available. The given algorithm must provide a digital signal that will be transformed into voltage supply for the servo motor through a digital-to-analog $(A D)$ converter. The dynamic equations, together with the nominal values for physical parameters, are provided:

$$
\dot{w}=\frac{\kappa u-w}{\tau}, \quad \dot{\theta}=w
$$

where $\boldsymbol{\theta}$ and $\mathbf{w}$ are respectively the angular position and the angular speed of the servo, $\mathbf{u}$ is the input voltage, and the rest of physical parameters are given below:

$$
\begin{aligned}
\kappa & =27[1 / V \bullet s], \\
\tau & =0.253[s]
\end{aligned}
$$




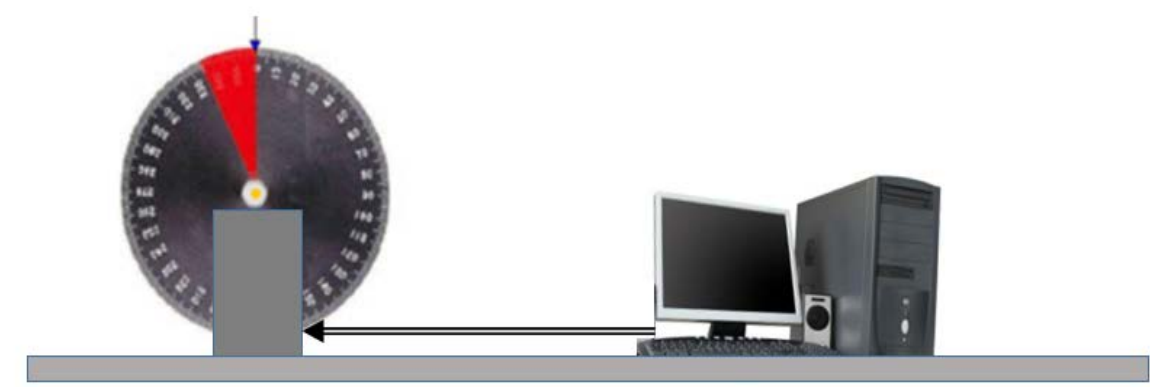

Figure 2. Computer-based control of the angular position of a servomechanism where rotational position is measured by an encoder.

\subsection{Time Scheduling and related activities}

Although theoretical lessons are taught following the classical method, in this first approach the proposed PBL method is integrated in such a way that it does not result to be quite disruptive with respect to other related teaching subjects in order to allow a smooth transient stage. The different activities of the PBL is described below:

- Presentation and explanation of the problem to be solved: no more than 20 minutes at the beginning of the teaching session is dedicated at this stage. Teachers invite to participate in a brief discussion with their students which allows instructor to obtain an immediate feedback. Discussion requires the learners to think critically on the stated problem and encourage students to address the problem. The presentation is made after around three weeks, in order to ensure that the minimum background necessary to understand the problem has been provided.

- A short written questionnaire of no more than 10 minutes to concisely summarize what students have understood about the stated problem, and in general to collect students' opinion about the relevance and interest of control engineering in real-life. Some of the questions to be stated are: why do you think that control engineering is interesting and useful for your career? what are the most difficulties that you have found in this subject? Give some example where automatic control is necessary.

- Periodic short debates among students, with the objective of allowing them to gather information to support their view and also explain it to their classmates. These debates not only give the student a chance to participate in a fun activity, but it also lets them gain some experience with giving a verbal presentation an active way for students. Moreover, it allows instructor to easily perform a follow-up of the progress of their students.

- Private meetings with students in order to make a closer follow-up of their progress and detection of possible misleading or difficulties with the objective to prevent them to give wrong solutions. At this stage the evaluation can be addressed by observing the attitude of each student and their degree of interest and participation.

\subsection{Communication channels}

This section describes the two communication channels used for the PBL method: face-to-face classes and the Moodle platform, and the way they are used during the PBL process:

- Face-to-face (F2F) sessions: through the organization of short debates among students and private meetings.

- Moodle platform (MP): It is a tool provided by the University. In our case, we will use the Moodle platform with the following objectives: (i) facilitating access to different resources and materials (ii) allowing students to upload their results and (iii) allowing students and teacher to share possible difficulties or suggestions.

The use of the communication channels is as described below:

- F2F sessions will be used to explain in the classroom the PBL method and to present the challenges that they must accomplish.

- MP will be used to publish the work description and instructions in a PDF file, together with the media contents (HTML, CSS, Javascript files). 
- Once students have downloaded all files, they will be able to work locally in their computers, that is to say, without being necessary on-line connection.

- Once students have finished their works, they will create a brief document explaining the procedure that they have followed to solve the problem, the main conclusions and results. The document, together with the modified files, will be delivered by uploading to Moodle platform.

\section{CONCLUSIONS}

One of the key aspects in teaching engineering subjects with strong theoretical background is how to engage students' interest as well as facilitating them to handle educational resources to fill the gap between the theoretical contents and their real implementation in the industry.

This paper has presented a problem-based active learning (PBL) method for computer-based control engineering subjects. The proposed method takes advantage of the on-line availability of free-of-charge software resources, which implies that it is not necessary to invest extra money. Moreover, students are facilitated to work at any place and any time, releasing them of timetable constraints and promoting thus their autonomy. On the other hand, the PBL has been designed in such a way that it does not imply substantial modifications with respect to previous academic years. Students are challenged to solve engineering problems as if it were a game for them making use of the previously developed virtual labs, which can be downloaded from the Moodle Platform.

It is worthwhile mentioning that the proposed method can easily be adapted to other science subjects by simply creating new EJS illustrative applications, or modifying some existing available EJS applications with the objective to reuse other previous existing developments for each specific teaching subject. Thus, new friendlier and simpler tools will be available to help the student to assimilate the contents explained in class through the proposed PBL method.

\section{ACKNOWLEDGEMENTS}

This work is supported by the Universidad de Zaragoza project PIIDUZ_19_342 Desarrollo e implantación de un modelo basado en aula invertida y metodologías activas para asignaturas de informática e ingeniería de sistemas.

\section{REFERENCES}

[1] Michel, Norbert, John James Cater III, and Otmar Varela. "Active versus passive teaching styles: An empirical study of student learning outcomes." Human resource development quarterly, vol. 20, no. 4, pp. 397-418, 2009.

[2] Wingfield, S. S, Black, G. S. "Active versus passive course designs: The impact on student outcomes". Journal of Education for Business, vol. 81, no. 2, pp. 119-123, 2005.

[3] Bloom, Benjamin S. "Taxonomy of educational objectives. Vol. 1: Cognitive domain." New York: McKay, 1956.

[4] Hackathorn, J., Solomon, E. D., Blankmeyer, K. L., Tennial, R. E., Garczynski, A. M. "Learning by Doing: An Empirical Study of Active Teaching Techniques". Journal of Effective Teaching, vol. 11, no. 2, pp 40-54, 2011

[5] Mayer, R. E. "Rote versus meaningful learning". Theory into practice, vol. 41, no. 4, pp. 226-232, 2002.

[6] Deci, E. L. "Intrinsic motivation". New York: Plenum, 1975.

[7] Trenshaw, K. F., Revelo, R. A., Earl, K. A., Herman, G. L. Using self-determination theory principles to promote engineering students' intrinsic motivation to learn. International Journal of Engineering Education, vol. 32, no. 3, pp. 1194-1207, 2016.

[8] Esquembre, F. "Easy Java Simulations: A software tool to create scientific simulations in Java". Computer physics communications, vol. 156, no. 2, pp.199-204, 2004.

[9] Hoff, A. V., Shaio, S. "Hooked on Java; Creating Hot Web Sites with Java Applets". Addison-Wesley Longman Publishing, Boston USA, 1995. 
[10] Flanagan, D. "JavaScript: the definitive guide". Sebastopol, 2006.

[11] Chaos, D., Chacón, J., Lopez-Orozco, J., Dormido, S. "Virtual and remote robotic laboratory using EJS, MATLAB and LabVIEW". Sensors, vol. 13, no. 2, pp. 2595-2612, 2013.

[12] R. Dormido, H. Vargas, N. Duro, J. Sánchez, S. Dormido-Canto, G. Farias, F. Esquembre, S. Dormido. "Development of a web-based control laboratory for automation technicians: The threetank system". IEEE Transactions on education, vol. 51, no. 1, pp.35-44, 2008.

[13] Christian, W., Esquembre, F. "Modeling physics with easy java simulations". The Physics Teacher, vol. 45, no. 8, pp. 475-480, 2007.

[14] Heradio, R., de la Torre, L., Galan, D., Cabrerizo, F. J., Herrera-Viedma, E., Dormido, S. "Virtual and remote labs in education: A bibliometric analysis". Computers \& Education, vol. 98, pp. 14-38, 2016.

[15] Allen, D. E., Donham, R. S., Bernhardt, S. A. "Problem-based learning". New directions for teaching and learning, no. 128, pp. 21-29, 2011 